\title{
MTZ WORLDWIDE
}

Liebe Leserin, lieber Leser,

im 73. Jahr ihres Erscheinens hat die MTZ nichts von ihrer Attraktivität für ihre Nutzer verloren, wie ich es immer wieder gerne höre und feststellen kann. Für die meisten unserer Leserinnen und Leser gehört sie zur Pflichtlektüre und zur Informationsquelle Nummer 1 unter den Medien in ihrem beruflichen Alltag. Und das erstaunlicherweise in mehr als 50 Ländern auf allen Kontinenten.

Damit auch immer mehr unserer englischsprachigen Nutzer uneingeschränkt unsere Inhalte verstehen können, wurde vor einigen Jahren MTZ worldwide als sogenanntes E-Magazin gegründet und hat zwischenzeitlich viele Abnehmer gewonnen. Dieses elektronische Medium enthält alle Fachbeiträge der MTZ in einer englischen Fassung. Zukünftig sollen noch mehr Berichte aus der internationalen Motorenentwicklung dazukommen. Eine Test-Ausgabe können Sie unter springervieweg-service@ springer.com anfordern. Für eine Empfehlung im Kollegenkreis wäre ich Ihnen dankbar, damit dieses schnelle Fachmedium noch eine größere Verbreitung findet.

Mit unseren Veranstaltungsaktivitäten (ATZlive) zu aktuellen Themen unseres Fachgebiets gelingt es uns seit Jahren erfolgreich, unsere Leserschaft miteinander $\mathrm{zu}$ vernetzen und $\mathrm{zu}$ einem fruchtbaren Erfahrungsaustausch zu bewegen. Daher darf ich Sie heute schon auf folgende Veranstaltungen im zweiten Halbjahr hinweisen: 14. MTZ-Fachtagung „Virtual Powertrain Creation“, 25./26. September in Esslingen; 5. MTZ-Fachtagung „Ladungswechsel im Verbrennungsmotor“, 23./24. Oktober in Stuttgart; 7. Internationale MTZ-Fachtagung „Heavy-Duty-, On- und Off-Highway-Motoren“, 6./7. November in Nürnberg.
Ich nutze an dieser Stelle die Gelegenheit, Sie auch zu ermuntern, unsere vielseitigen Online-Initiativen regelmäßig in Anspruch zu nehmen. Via ATZonline.de erhalten Sie tagesaktuelle Meldungen aus der Branche und können kostenlos den zweimal wöchentlich erscheinenden Newsletter mit ausführlicheren Berichten abonnieren. Und wenn Sie Lust dazu verspüren, dann diskutieren Sie im ATZblog mit und sorgen so für einen regen Meinungsaustausch!

\section{Herzlichst}

Ihr

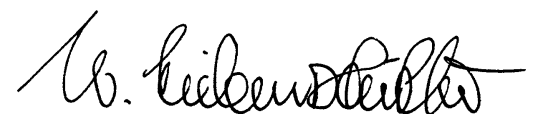

\section{WOLFGANG SIEBENPFEIFFER,}

Chefredakteur und Herausgeber

Stuttgart, im Februar 2012

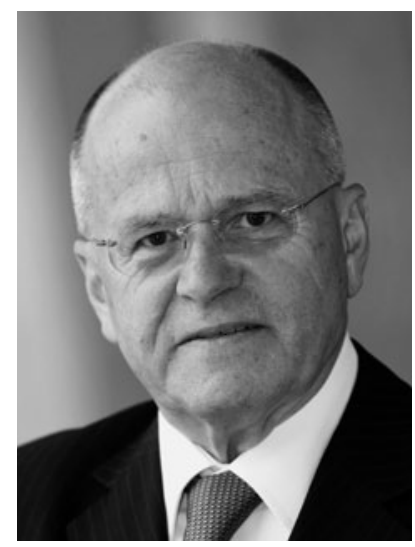

\section{Engine}
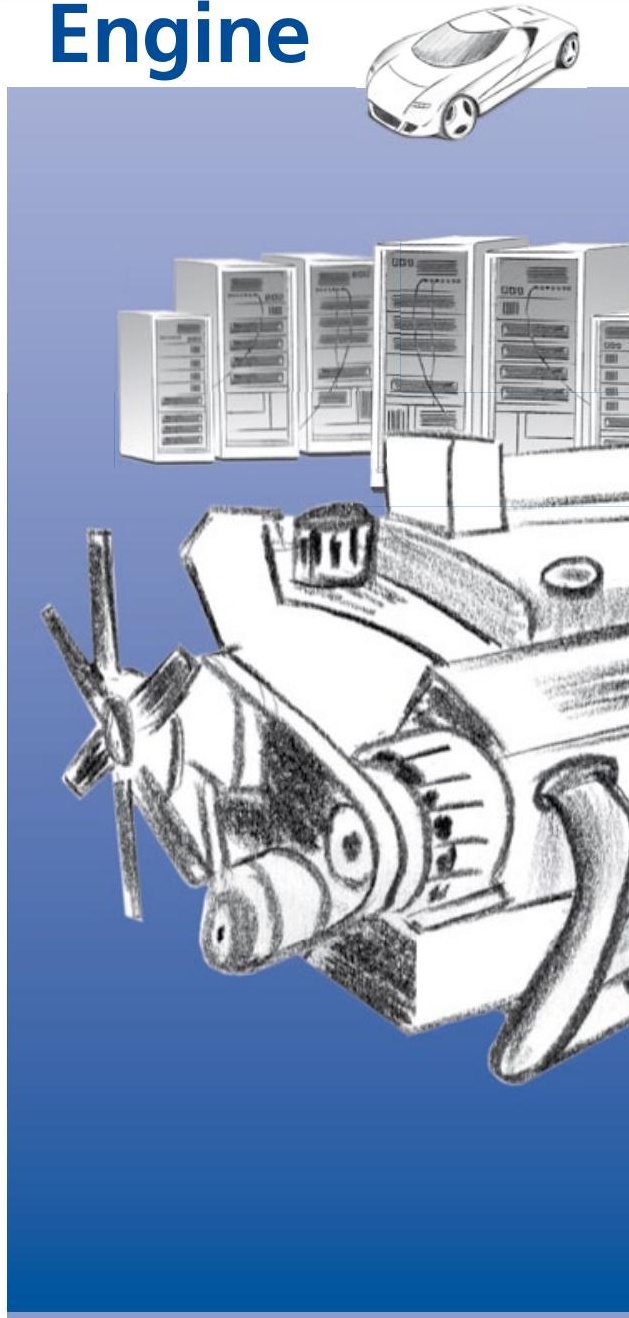

Steuergeräteentwicklung

im virtuellen Testfahrzeug

- Durchgängige Simulationsumgebung für MiL, SiL, HiL

- Zuverlässige Motormodelle mit passendem Detaillierungsgrad

- Nahtlose Integration Ihrer Modellteile

- Übersichtliche Bedienung,

Datenmanagement und Auswertung

\section{Top-Simulationsjobs Mehr erfahren und bewerben: www.tesis-dynaware.com/jobs}

